\title{
A SUSTENTABILIDADE AMBIENTAL E OS CONHECIMENTOS TRADICIONAIS NO MANEJO DO PIRARUCU NA AMAZÔNIA
}

\author{
ENVIRONMENTAL SUSTAINABILITY AND TRADITIONAL KNOWLEDGE IN \\ MANAGEMENT IN THE AMAZON PIRARUCU
}

${ }^{1}$ Kátia Cristina Cruz Santos

${ }^{2}$ Moises Seixas Nunes Filho

\section{RESUMO}

O manejo da pesca constitui-se numa intervenção humana causal ou programada diretamente do meio natural ou em cativeiro, com o fito de promover a manutenção, recuperação ou controle das populações de peixes, contribuindo com a estabilidade dos ecossistemas, dos processos ecológicos ou dos sistemas produtivos. Objetivo deste trabalho é estudar e estabelecer a relação entre a conservação da biodiversidade no contexto da sustentabilidade através dos conhecimentos tradicionais baseado no manejo do pirarucu da Amazônia. Neste sentido o deslinde desse problema foi objeto de pesquisa teórica, utilizando-se do método dedutivo e de consulta bibliográfica.

Palavras-chave: Conservação, Biodiversidade, Conhecimentos tradicionais, Manejo

\begin{abstract}
The management of fisheries is in a causal or programmed human intervention directly from the wild or in captivity, with the aim of promoting the maintenance, recovery or control of fish stocks, contributing to the stability of ecosystems, ecological processes or systems production. Objective of this work is to study and establish the relationship between the conservation of biodiversity in the context of sustainability through traditional knowledge based on the management of the Amazon arapaima. In this sense the disentangling of this problem was theoretical research object, using the deductive method and bibliographic.
\end{abstract}

Keywords: Conservation, Biodiversity, Traditional knowledge, Management

\footnotetext{
${ }^{1}$ Mestre em Direito Ambiental pela Universidade do Estado do Amazonas - UEA, Amazonas (Brasil). Professora pela Universidade do Estado do Amazonas - UEA, Amazonas (Brasil). E-mail: katia_cristina_cruz@hotmail.com

${ }^{2}$ Mestrando em Ciências Ambientais pela Universidade de Brasília - UnB, Distrito Federal (Brasil).

E-mail: nunes_moises@hotmail.com
} 


\section{INTRODUÇÃO}

A contaminação do meio ambiente acarreta perdas para os entes da natureza, para as atividades econômicas e para a manutenção ou melhoria do bem-estar humano, pois ocorrem modificações no processo produtivo, na saúde humana, no hábitat natural, na vegetação, no clima, na qualidade do ar, na vida animal, nos monumentos históricos e nas demais belezas da biodiversidade.

Para Mota (2006), as alterações ambientais dão origem aos impactos - cujos efeitos recaem sobre o meio ambiente natural e modificam a cadeia alimentar da natureza e os valores hedônicos do capital natural -, e às externalidades - cujos efeitos positivos ou negativos recaem sobre os seres humanos, melhorando ou piorando seus bem-estares.

A Constituição Federal de 1988 foi a primeira a abordar sobre o Meio Ambiente e destina um capítulo à proteção deste, qual seja o capítulo VI do Título VIII. O Tema foi inserido de forma proposital nesse capítulo, com o escopo relacionar o meio ambiente à sociedade. Neste sentido, a proteção do meio ambiente é considerada um direito transindividual, pois ultrapassa o conceito de indivíduo e se aproxima da noção de sociedade, sendo seus titulares relacionados entre si, em razão do bem jurídico tutelado, o meio ambiente.

A preocupação ambiental já está ratificada por diversos acordos internacionais e por inúmeros entendimentos empresariais de que a conservação/preservação do meio ambiente é a mais importante âncora para o desenvolvimento.

Para Baltodano (2003), os recursos da biodiversidade, os elementos que a compõem e o conhecimento tradicional associado, tem estado sempre disponíveis e em sua maioria são compartilhados abertamente entre vizinhos e visitantes, com exceções das tradições ancestrais que mantém certos segredos, sobretudo à práticas de caráter religioso ou cosmogônico.

Destaca-se que o conhecimento tradicional não está marcado pela antiguidade e inutilidade, mas é caracterizado pela forma de sua constituição.

\footnotetext{
Este conhecimento ocorre de forma coletiva, oral e intergeracional, estando intimamente ligado com a forma de relação que esta comunidade possui com a natureza. Ou seja, o saber é difundido oralmente entre os integrantes da comunidade, desenvolvido de forma coletiva, porque é fruto do trabalho de vários de seus membros, e intergeracional porque a aplicação que se faz de determinado conhecimento passa pela interpretação e atualização das gerações presentes. (WANDSCHEER, 2008, p. 6339)
}

Portanto, este conhecimento depende do meio ambiente em que vivem determinadas comunidades, pois estas possuem uma estrutura social de contato e respeito com a natureza, o que garante a sua utilização presente e para as futuras gerações. Cada comunidade desenvolve 
técnicas de manejo e utilização dos recursos naturais de acordo com a disponibilidade destes nas áreas que ocupam, e em razão da abundância ou da escassez desenvolvem seus ritos e modos de vida. Por isso que as peculiaridades das sociedades estão relacionadas com seus territórios.

É importante compreender que essa diversidade biológica não está dissociada da diversidade social e cultural, tendo em vista que a atuação do homem foi fundamental para a constituição do meio ambiente de hoje.

Com efeito, o manejo possibilita o uso sustentável dos recursos naturais preservandoos, restaurando-os, recuperando-os e produzindo maiores benefícios sem exaurir o seu potencial, e assim, satisfazendo as necessidades e aspirações das gerações presentes e das vindouras.

A ideia de natureza intocada já está ultrapassada e a interação do homem com a natureza comprovada. Por isso que no relacionamento do homem com a natureza, há uma influência significativa na preservação e conservação do ambiente natural, de modo que a presença e a atuação das sociedades ao longo dos anos foi essencial para a configuração dos espaços naturais de hoje.

Nosso artigo científico tem objetivo geral, estudar e estabelecer a relação entre a conservação da biodiversidade no contexto da sustentabilidade através dos conhecimentos tradicionais baseado no manejo do pirarucu da Amazônia. Temos a seguinte problemática, a busca pela sustentabilidade ambiental é alcançada com o manejo do pirarucu efetuado mediante conhecimentos tradicionais?

Portanto o deslinde de tais questionamentos será feito por meio de pesquisa teórica, utilizando-se do método dedutivo e de consulta bibliográfica, além de sítios de reconhecida confiabilidade que tragam artigos científicos sobre a matéria, bancas de dissertações e teses.

\section{SUSTENTABILIDADE}

A crise ambiental introduz limitações que ressignificam o curso do pensamento social, especialmente a partir dos anos de 60, quando o mundo assistiu a uma revolução social através dos movimentos contra culturais, que fizeram crítica aos padrões de consumo e propõem limites ao crescimento (Clube de Roma). Surge o conceito de capacidade de suporte em ecologia e, em seguida, o conceito de sustentabilidade, como tentativa de compatibilizar o crescimento populacional humano com a preservação dos recursos. (LEFF, 2000).

No que se refere ao surgimento dos sujeitos ecológicos, a expansão da consciência ambiental nos anos de 70 reflete uma correspondência entre o que se vê na TV e no mundo real. 
A observação da degradação ambiental é o principal fator agregador e iniciador dessa consciência.

Há uma passagem dos problemas ambientais para uma segunda escala de amplitude (chuva ácida, aquecimento global, buraco na camada de ozônio, etc.), o que promove na sociedade uma percepção de crise. Esta tendência propõe que se imponham limites para a industrialização que, se controlada, poderia minimizar a poluição e os problemas ambientais.

Desde a definição da Comissão Brundtland em 1987, para qualificar o "desenvolvimento" e buscar a continuidade e a prosperidade de vida no século XX, até hoje, o termo tem sido utilizado inclusive para se referir a diversas finalidades.

A partir do Relatório Brundtland, foi convencionado que a proteção ao meio ambiente e a promoção do desenvolvimento econômico são objetivos intimamente relacionados, e os países passaram a defender a possibilidade de haver "desenvolvimento sustentável". Nesta perspectiva, para que as economias nacionais cresçam e sejam promissoras, os recursos naturais devem ser conservados. (NEIMAN et al, 2014, p. 34)

Esse é o cenário que nos ajuda a entender o movimento ecologista que surge no final do século XX, com todas as suas nuanças. "Ecologizar” a sociedade e as políticas públicas passam a significar a introdução da variável ecológica onde antes só havia a preocupação econômica. Mas essa nova visão não mexe essencialmente com o paradigma central do capitalismo, apenas otimiza os processos produtivos.

A avaliação dos resultados da reunião de Estocolmo pela ONU, dez anos depois, mostrou que os esforços empreendidos ficaram muito aquém do necessário (Le Prestre, 2000).

A consequência foi a formação da Comissão Mundial sobre Meio Ambiente e Desenvolvimento (CMMAD), dirigida pela ex-primeira-ministra norueguesa Gro Harlen Brundtland, cujo relatório de 1987 (Our common future) tinha como missão propor uma agenda global para a mudança. Constituiu o maior esforço então conhecido para conciliar a preservação do meio ambiente com o desenvolvimento econômico, cujo porto de chegada denominou-se Desenvolvimento Sustentável. Sua definição tornou-se clássica e objeto de um grande debate mundial (Lenzi, 2006): "Desenvolvimento sustentável é o desenvolvimento que satisfaz as necessidades do presente sem comprometer a capacidade das gerações futuras em satisfazer suas próprias necessidades”. A força e a fraqueza dessa definição encontram-se justamente nessa fórmula vaga, pois deixam-se em aberto quais seriam as necessidades humanas atuais, e mais ainda as das gerações futuras. Introduz-se a noção da intergeracionalidade no conceito de sustentabilidade, associando-a à noção de justiça social (redução das desigualdades sociais e direito de acesso aos bens necessários a uma vida digna) e aos valores éticos (compromisso com as gerações futuras). 
No final do século XX, período em que emerge na humanidade a noção de sua vulnerabilidade, enquanto base natural, é também o momento em que quanto mais resposta se obtém da ciência mais perguntas as respostas geram.

O novo conceito cultural de sustentabilidade, bem distante de ser amplamente aceito, não é compreendido, endossado ou seguido pelos indivíduos na sociedade.

A razão do conceito de sustentabilidade não ter sido ainda abraçada, nem no nível individual nem no coletivo, é que as pessoas não perceberam as relações entre os domínios do social, do econômico e do ambiental. Problemas ambientais são entendidos pelas pessoas como problemas de saúde, que podem se tornar problemas de aprendizagem, etc.: todos os domínios interagem. (UZZELL, 2004).

"Pequenas mudanças no modo de vida devem acontecer para que haja sustentabilidade, caso contrário, segundo os ambientalistas, o consumo desenfreado de recursos pode levar o sistema civilizatório à autodestruição.” (NEIMAN et al, 2014, p. 34)

“A sustentabilidade é uma imposição de contrabalançar os sistemas e os fluxos de interdependência das relações entre eles. Não é outra coisa além de uma obrigação de conservação das espécies." (NEIMAN et al, 2014, p. 35)

Na visão da Organização das Nações Unidas (ONU), a sustentabilidade envolve os seguintes aspectos: conservação do solo, da água e dos recursos genéticos animais e vegetais, além de não degradar o ambiente, ser tecnicamente apropriado, economicamente viável e socialmente aceito (GIORDANO, 2005).

\begin{abstract}
A noção de sustentabilidade incorpora uma clara dimensão social e implica atender também as necessidades dos mais pobres de hoje, outra dimensão ambiental abrangente, uma vez que busca garantir que a satisfação das necessidades de hoje não podem comprometer meio ambiente e criar dificuldades para as gerações futuras. Nesse sentido, a idéia de desenvolvimento sustentável carrega um forte conteúdo ambiental e um apelo claro à preservação e à recuperação dos ecossistemas e dos recursos naturais (BUAINAIN, 2006, p. 47).
\end{abstract}

Altieri (2008, p. 82) diz que "definida de forma ampla, sustentabilidade significa que a atividade econômica deve suprir as necessidades presentes, sem restringir as opções futuras.

Kamiyama (2011) diz que a sustentabilidade está cada vez mais conhecida e utilizada em diversos setores da economia, mas não há um conceito definitivo, pois cada pessoa tem uma percepção sobre a utilização dos recursos naturais e o desenvolvimento econômico e social. 


\section{CONHECIMENTOS TRADICIONAIS: CARACTERÍSTICAS GERAIS}

Os conhecimentos desenvolvidos pelas comunidades tradicionais não se limitam àqueles de natureza prática, associados à sua alimentação e à sua sobrevivência. Segundo LéviStrauss (2006), as comunidades tradicionais apresentam uma pré-disposição natural à busca pelo conhecimento do entorno em que vivem. Do conhecimento dos biomas em que vivem, os membros destes grupos identificam as aplicações e qualidades dos elementos constitutivos destes biomas que podem servir à sua subsistência e à melhoria da qualidade de vida do ser humano em geral.

Um entendimento recorrente e simplista de Conhecimentos Tradicionais compreende apenas aqueles conhecimentos técnicos associados aos recursos da biodiversidade, os quais são conservados por comunidades indígenas. Esta definição estabelece dificuldades para uma compreensão correta do alcance do termo, pois nem todos os detentores de conhecimentos tradicionais são povos indígenas e nem todos os Conhecimentos Tradicionais se associam à biodiversidade. Os Conhecimentos Tradicionais indígenas constituem tão-somente uma categoria de Conhecimentos Tradicionais, diferenciando-se dos demais pelo grupo que os detêm.

De qualquer forma, a origem étnica e o arcabouço cultural diferenciado dos detentores dos Conhecimentos Tradicionais desempenham um papel central na construção de sua definição. Um determinado conhecimento será ou não caraterizado como "tradicional" dependendo, dentre outros fatores, de quem o conserva e exerça titularidade. Conhecimentos Tradicionais são detidos por grupos marginalizados e culturalmente distintos, portadores de estilos de vida "tradicionais", ou seja, seguindo as tradições de seus antepassados, estes grupos extraem seus meios de subsistência do meio ambiente natural em que vivem, sem lançar mão de recursos e tecnologias modernas.

O vínculo do tema a grupos social e economicamente marginalizados torna-o de relevância aos direitos humanos.

O predicado "tradicional" pode sugerir que os conhecimentos integrantes desta categoria de conhecimentos técnicos são transmitidos em formato "fossilizado", desde tempos imemoriais. De fato, os conhecimentos tradicionais são difundidos, desde tempos imemoriais, pelas gerações mais velhas às mais jovens, em suas relações diárias.

No entanto, o termo não deixa transparecer a atividade criativa contemporânea dos membros das comunidades tradicionais, que atualizam os conhecimentos antigos em face das demandas presentes. 
Deve-se, pois, ter claro que a natureza "tradicional" dos conhecimentos de comunidades tradicionais não implica sua antiguidade. "Tradicional” confere conteúdo cultural aos conhecimentos, interligando-os à identidade cultural de um determinado grupo humano, ou seja, é tradicional aquele conhecimento gerado e utilizado como parte das tradições de um determinado grupo. Por conseguinte, novos conhecimentos são desenvolvidos ininterruptamente pela atividade intelectual dos membros de comunidades tradicionais.

Sem conhecimento, um elemento da natureza é apenas um recurso desconhecido, despido de valor. Os recursos biológicos e os conhecimentos constituem para as comunidades tradicionais, respectivamente, uma extensão de sua própria sociedade e uma emanação do mundo espiritual no mundo material.

Conforme Rodriguez:

A primeira frente surge de uma preocupação trazida à tona durante a Conferência de Estocolmo (1967), para com as obras não publicadas e com aquelas em que o autor não poderia ser individualmente identificado. É nesse registro que a tradição popular passa a ser inicialmente debatida em âmbito internacional, sob a rubrica do termo folclore. As características de oralidade e de pertencimento a um grupo ou comunidade foram entendidas como fragilidades desses saberes, justificando a proteção dessas expressões culturais. A segunda frente conta com o papel ativo dos povos indígenas e dos movimentos sociais ambientalistas que, ao discutirem alternativas de desenvolvimento e começarem a acompanhar as reuniões da ONU na década de 1980, abriram espaço para tratar dos conhecimentos dos povos tradicionais relacionados à proteção da biodiversidade (RODRIGUEZ, 2011, p. 48).

Conhecimentos Tradicionais conforme explica Kiewelo:

Ideais e pressupostos relativos a um conhecimento interno, diferente do conhecimento da sociedade circundante, centrado na localidade em que é utilizado e abarcando o conhecimento exógeno introduzindo na comunidade ao longo de determinado período; Informação sistemática, mas que se mantém na informalidade, na oralidade; Conjunto de todos os saberes e práticas, implícitas e explícitas, aplicados na vida socioeconômica e ecológica. Conjunto de experiências e conhecimento de um grupo étnico, base para decisões no âmbito de conflitos familiares, criados de forma endógena, com elementos externos, mas que são integrados internamente, por meio de capacidade intrínseca de absorção de conhecimentos relevantes; Conhecimento local, tradicional e único, desenvolvido em razão de condições específicas de uma dada comunidade numa dada área geográfica (KIEWELO, 2009, p. 160).

Para Leutzinger conhecimentos tradicionais corresponde aos "saberes que possuem as populações tradicionais, sendo gerados de forma coletiva e ao longo do tempo e consolidados em virtude da experiência e de uma estreita relação com o meio natural”. (LEUTZINGER, 2009, p. 230).

Os conhecimentos tradicionais, portanto, nascem no seio das comunidades tradicionais e indígenas, fruto da interação do homem com o meio natural, operando 
com lógicas perceptuais e sensíveis e estabelecendo uma relação não utilitarista, mas de simbiose. Para essas sociedades há uma interligação orgânica entre o mundo natural, sobrenatural e a organização social. Esses saberes englobam um conjunto de procedimentos de aprendizagem e de divisão de conhecimentos, um acervo de práticas e processos que vão dando sustentação à vida das pessoas e dos grupos que os foram criando. (SOUZA e LOCATELLI, 2015, p. 396)

Para Soares:

Os conhecimentos tradicionais são os saberes e técnicas que os índios e outras comunidades locais (tais como os quilombolas, os caiçaras, os seringueiros, os pescadores, os ribeirinhos, entre outras) têm e utilizam para sua sobrevivência e para o atendimento de necessidades culturais, espirituais, materiais e financeiras das presentes e futuras gerações. São conhecimentos sobre as potencialidades dos recursos naturais e sobre formas e técnicas de manejo e sua gestão, bem como sobre métodos de caça, pesca, processamento de alimentos e propriedades fitoterápicas de elementos da flora (SOARES, 2009, p. 195).

\subsection{Discussões legais sobre a Proteção do Conhecimento Tradicional}

Os interesses pelos recursos biológicos tornam-se cada vez mais evidentes, basta uma simples observação do desenvolvimento da legislação nacional. Como exemplo podem-se citar a lei ${ }^{\circ}$ 6.938, de 31 de agosto de 1981, que dispõe sobre a Política Nacional do Meio Ambiente, seus fins e mecanismos de formulação e aplicação, com as alterações promovidas pela lei $\mathrm{n}^{\circ}$ 9.960, de 28 de janeiro de 2000, que em seu artigo $2^{\circ}$, III já previa o planejamento e fiscalização do uso dos recursos ambientais.

O decreto legislativo $\mathrm{n}^{\circ} 2$ de 1994, aprovou o texto da Convenção sobre Diversidade Biológica, assinada durante a Conferência das Nações Unidas sobre Meio Ambiente e Desenvolvimento, realizada na cidade do Rio de Janeiro, ao período de 5 a 14 de junho de 1992, que estabeleceu em seu artigo $1^{\circ}$ os objetivos a serem cumpridos pelos signatários, dentre eles a conservação da diversidade biológica, a utilização sustentável de seus componentes e a repartição justa e equitativa dos benefícios derivados da utilização dos recursos genéticos, mediante, inclusive, o acesso adequado aos recursos genéticos e a transferência adequada de tecnologias pertinentes, levando em conta todos os direitos sobre tais recursos e tecnologias, e mediante financiamento adequado.

Além de estabelecer em seu artigo 8, “j”, a necessidade de que os países signatários respeitem, preservem e mantenham os conhecimentos, inovações e práticas das comunidades locais e populações indígenas com estilo de vida tradicionais. 


\subsection{A Convenção Sobre Diversidade Biológica-CDB}

Convenção Sobre Diversidade Biológica-CDB é considerada uma das mais importantes referências legislativas, no que tange à questão da proteção dos conhecimentos tradicionais associados, em nível mundial. Por meio dela, os Estados (lato-senso), têm o reconhecimento para que seus governos possam explorar seus recursos genéticos, de forma soberana (ALENCAR, 2006)

Neste sentido, no art. $3^{\circ}$, pode ser verificado o princípio basilar da CDB, in verbs:

Art. $3^{\circ}$ - "Os Estados, em conformidade com a Carta das Nações Unidas e com os princípios de Direito Internacional, têm o direito soberano de explorar seus próprios recursos segundo suas políticas ambientais, e a responsabilidade de assegurar que atividades sob sua jurisdição ou controle não causem dano ao meio ambiente de outros Estados ou de áreas além dos limites da jurisdição nacional”.

Em razão do exposto, conclui-se que os recursos genéticos são de soberania de cada país, em contrapartida, o conhecimento tradicional associado à biodiversidade pertence a seus detentores, quais sejam povos indígenas e populações tradicionais. Neste contexto Cunha (2006, p. 61), "considera que o reconhecimento e retribuição dos conhecimentos tradicionais a seus detentores, consiste numa forma de beneficiar os países e toda humanidade".

\subsection{Constituição Federal}

É importante ressaltar que a sociodiversidade, caracterizada pelo conjunto de tradições e cultura dos povos autóctones e populações tradicionais, os quais muitas vezes se utilizam da biodiversidade para manifestá-las, também possui proteção constitucional, por força do art. 215, $\S 1^{\circ}$, da Constituição Federal, in verbs: "O Estado protegerá as manifestações das culturas populares, indígenas e afro-brasileiras, e das de outros grupos participantes do processo civilizatório nacional".

A biodiversidade também está protegida pela Carta Magna no art. 225, $\S 1^{\circ}$, II, o qual preconiza que "é dever do Poder Público e da coletividade, preservar a integridade do patrimônio genético do País e fiscalizar as entidades dedicadas à pesquisa e manipulação de material genético". 


\section{MANEJO DA PESCA DO PIRARUCU NA AMAZÔNIA}

Na década de 1970, devido à intensa exploração comercial, a população de pirarucus entrou em declínio, levando o Instituto Brasileiro do Meio Ambiente e dos Recursos Naturais Renováveis - IBAMA em 1989, a estabelecer um tamanho mínimo de captura $(150 \mathrm{~cm})$ e, em 1990, o período de defeso reprodutivo ( $1^{\circ}$ de dezembro a 31 de maio) para esta espécie. Como essas medidas surtiram pouco efeito prático devido à grande extensão geográfica da Amazônia e a falta de fiscalização efetiva, em 1996 foi proibida no Amazonas, qualquer tipo de captura e venda de pirarucus (Portaria 8/96), sendo permitida apenas em áreas manejadas ou provenientes de cultivo (SANTOS ; SANTOS, 2005).

O manejo possibilita o uso sustentável dos recursos naturais preservando-os, restaurando-os, recuperando-os e produzindo maiores benefícios sem exaurir o seu potencial, e assim, satisfazendo as necessidades e aspirações das gerações presentes e das vindouras. O manejo da pesca constitui-se numa intervenção humana causal ou programada diretamente do meio natural ou em cativeiro, com o fito de promover a manutenção, recuperação ou controle das populações de peixes, contribuindo com a estabilidade dos ecossistemas, dos processos ecológicos ou dos sistemas produtivos.

A Lei $n^{\circ}$ 9.985, de 18 de julho de 2002 ao instituir o Sistema Nacional de Unidades de Conservação da Natureza, em seu artigo $2^{\circ}$, inciso VIII, definiu manejo como sendo "todo e qualquer procedimento que vise assegurar a conservação da diversidade biológica e dos ecossistemas".

No Brasil os dispositivos do art. 225 da Constituição Federal impõem que a utilização dos recursos naturais devem visar não só as gerações presentes, mas também às gerações futuras.

Os objetivos do manejo estão em franca mudança em todo o mundo assim como a visão dos tomadores de decisão sobre o uso dos recursos naturais. Este autor indica três tendências que condicionam a direção que vem seguindo manejo:

I- o surgimento de novos objetivos voltados para a conservação dos recursos naturais a partir da Convenção da Biodiversidade e do Código da Pesca Responsável;

II- Mudança dos padrões de uso do recurso pesqueiro, surgidas a partir do êxodo rural, levando à necessidade de um abastecimento maior dos centros urbanos com consequências de sobre pesca sobre os estoques, aumento de preço e intensificação da captura das espécies maiores, e o desenvolvimento da pesca esportiva em detrimento da pesca que visa ao consumo;

III- emergência de duas políticas voltadas, principalmente, à pesca. 
Os manejos comunitários de pesca vêm se desenvolvendo desde a década 1970 nas várzeas amazônicas (MCGRATH, 1993; XIMENES, 2008). Nas regiões do alto Solimões e Baixo/Médio Amazonas vêm-se consolidando a partir da intervenção de projetos governamentais e apoio de instituições externas que atuam no fortalecimento da organização comunitária

No cenário nacional, a pesca está incluída entre as quatro maiores fontes de fornecimento de proteína animal para o consumo humano. Além de sua importância para a nutrição, os recursos pesqueiros requerem uso e manejo sustentável por sua importância socioeconômica (gerador de trabalho e renda), ambiental e cultural (IBGE, 2015). De acordo com estudos da FAO (2001) 95\% dos pescadores do mundo são pescadores artesanais, responsáveis pela captura de aproximadamente metade da produção mundial destinada ao

O manejo comunitário da pesca compreende as ações de manejo tomadas ao nível local, pelos próprios usuários/comunitários.

De acordo com Cerdeira (2009), o manejo comunitário de pesca na Amazônia é uma resposta da sociedade civil à falta de gestão adequada à região e à ausência de uma política pesqueira que atenda os anseios locais. Esta forma de manejo é uma alternativa ao modelo convencional imposto pelo poder público, que propõe um ordenamento local à pesca que sustente os modos de vida da população moradora.

O modelo convencional para Ruffino (2005 apud Cerdeira, 2009) tem por base três ideias: I) os recursos pesqueiros são de domínio da união e devem ser acessíveis; II) os usuários não tem capacidade de manejo do recurso sem a supervisão do Estado; e III) o rendimento máximo sustentável pode ser estimado.

$\mathrm{O}$ autor justifica que a incapacidade do Estado em regular efetivamente a pesca leva o recurso à condição de livre acesso, significando "sem controle"; que, com base nas afirmações de McGoodwin (1990 apud Cerdeira, 2009), apesar dos pescadores serem considerados sem capacidade de controle da pressão excessiva sobre o recurso e nem de conservá-lo por agências do governo, as experiências bem sucedidas com o manejo comunitário de pesca tem mostrado o contrário, as comunidades tem capacidade de controle social e baixa densidade populacional.

Esta capacidade de controle social que permite o monitoramento e o desenvolvimento do manejo comunitário segundo Ruffino (2005 apud Cerdeira, 2009), somente é possível se as comunidades envolvidas no manejo apresentarem nível de organização adequado. Neste sentido, os estudos de Benatti et al. (2003 apud Cerdeira, 2009) confirmam esta idéia ao citar a 
organização social, Cerdeira (2009) menciona que respostas sobre a eficácia do modelo de manejo comunitário para conservação dos estoques pesqueiros, principalmente os migradores, visto a abrangência geográfica limitada dos acordos de pesca, e os efeitos das medidas sobre os grupos usuários no que se refere ao seu desenvolvimento econômico e social são objetivos a serem alcançados em sistemas de monitoramento e avaliação dos impactos desses acordos.

\subsection{Regulamentação da Atividade Pesqueira no Brasil}

Nos termos do art. $7^{\circ}$ da Lei $\mathrm{n}^{\circ} 11.959 / 09$, o desenvolvimento da atividade pesqueira deve se dar de forma sustentável, através da gestão do acesso e uso dos recursos pesqueiros (I); da determinação de áreas especialmente protegidas (II); do controle e a fiscalização da atividade pesqueira (IX), entre outros.

Ao poder público compete a regulamentação da Política Nacional de Desenvolvimento Sustentável da Atividade Pesqueira, devendo estabelecer, no que concerne aos recursos pesqueiros $\left(\operatorname{art.} 3^{\circ}\right.$ ): os regimes de acesso (I); a captura total permissível (II); o esforço de pesca sustentável (III); os períodos de defeso (IV); as temporadas de pesca (V); os tamanhos de captura (VI); as áreas interditadas ou de reservas (VII); as artes, os aparelhos, os métodos e os sistemas de pesca e cultivo (VIII); a capacidade de suporte dos ambientes (IX); as necessárias ações de monitoramento, controle e fiscalização da atividade $(\mathrm{X})$; a proteção de indivíduos em processo de reprodução ou recomposição de estoques (XI). (CAMARGO; CAMARGO, 2010)

$\mathrm{O}$ ato autorizativo da atividade pesqueira deve assegurar (art. $5^{\circ}$ ): a proteção dos ecossistemas e a manutenção do equilíbrio ecológico, observados os princípios de preservação da biodiversidade e o uso sustentável dos recursos naturais (I); a busca de mecanismos para a garantia da proteção e da seguridade do trabalhador e das populações com saberes tradicionais (II); e, por fim a busca da segurança alimentar e a sanidade dos alimentos produzidos (III).

A Lei $n^{\circ} 11.959 / 09$, que dispõe sobre a Política Nacional de Desenvolvimento Sustentável da Aquicultura e da Pesca, regula as atividades pesqueiras, revoga a Lei $n^{\circ}$ 7.679/88, e dispositivos do Decreto-Lei no 221/67.

Referida Lei também trouxe a definição de atividade pesqueira, como “[...] todos os processos de pesca, explotação e exploração, cultivo, conservação, processamento, transporte, comercialização e pesquisa dos recursos pesqueiros". (art. $4^{\circ}$ da Lei $\left.n^{\circ} 11.959 / 09\right)$. Dessa forma, toda a cadeia de pesca é englobada, captura, transporte, beneficiamento, estocagem e comercialização. (CAMARGO; CAMARGO, 2010) 


\subsection{Exemplo de Manejo Participativo de Pirarucu (Arapaima gigas) na Reserva de Mamirauá}

A pesca é uma das principais atividades realizadas nas Reservas de Desenvolvimento Sustentável Mamirauá - RDSM e Amanã - RDSA, tanto como fonte de alimentação quanto de renda, sendo o pirarucu uma das espécies de peixe de maior importância econômica (QUEIROZ; SARDINHA, 1999).

A RDS Mamirauá destaca-se pela proposta inovadora do seu gerenciamento, o qual incorpora as populações locais na tomada de decisões, buscando compatibilizar a conservação da biodiversidade da reserva com a permanência das populações tradicionais nela residentes. A permanência dessas populações implica necessariamente o uso dos recursos naturais e, entre estes, destacam-se os recursos pesqueiros (QUEIROZ, 2005).

Neste sentido, a partir do Plano de Manejo aplicaram-se gradativamente medidas restritivas e normativas destinadas à regulamentação da pesca, elaboradas com participação da comunidade. Criou-se uma zona de preservação permanente circundada por zonas destinadas à exploração sustentada dos recursos naturais (MAMIRAUÁ, 1996).

O Instituto Mamirauá é uma organização gerida sob as regras do direito privado, embora mantenha características de instituição pública, obedecendo aos critérios de controle de gastos e a auditorias internas e externas. A instituição também tem um contrato de gestão com o governo federal, com metas anuais e indicadores de desempenho preestabelecidos. Seu objetivo é produzir conhecimento para subsidiar a conservação da biodiversidade pela gestão participativa com base científica em recursos naturais da Amazônia, promover a conservação das Reservas por meio do uso participativo e sustentado dos recursos naturais, e assegurar a melhoria da qualidade de vida das famílias que ali vivem (IDSM, 2006).

O manejo comunitário dos recursos pesqueiros pode ser entendido como os esforços das comunidades ribeirinhas em administrar a pesca local, criando reservas de lagos, defi nindo e implementando de forma coletiva medidas de controle de uso e restrição da entrada de pescadores externos (MCGRATH et al., 1993).

O manejo de pirarucu consiste no cumprimento de uma série de procedimentos, dentre eles a licença de pesca emitida pelo IBAMA - AM, anualmente. De forma geral, o sistema de manejo comunitário, ou manejo participativo, baseia-se na organização dos pescadores em associações ou colônias de pescadores; no estabelecimento de regras de uso e respeito à legislação vigente; no monitoramento anual dos estoques de pirarucu (contagem); na 
fiscalização e vigilância das áreas; no estabelecimento de cotas conservativas de pesca e na venda da produção (AMARAL, 2009).

O método de contagem de pirarucus foi desenvolvido pelo pesquisador Leandro Castello, em 2000, como uma adaptação ao modo tradicional de contagem feito pelos pescadores na hora de planejar sua pescaria. Isto porque esta espécie possui dois tipos de respiração, uma aérea e outra aquática. A respiração aérea é possível devido à modificação de sua bexiga natatória que estoca ar semelhante a um pulmão. Devido a esta característica, o peixe se adapta facilmente a águas com baixo teor de oxigênio, como no caso dos lagos de várzea (CASTELLO, 2004).

Quando um pirarucu vem à superfície para respirar, pescadores experientes são capazes, através da visão e audição, obter informações fundamentais para o manejo como quantidade de indivíduos existentes em um determinado corpo d'água e tamanho aproximado do peixe. Este método foi testado pela pesquisa desenvolvida em 1999 por Leandro Castello, em alguns lagos da RDS Mamirauá, sendo os resultados das contagens comparados com aqueles provenientes de estudos tradicionais de marcação e recaptura, obtendo-se uma forte relação entre as estimativas produzidas pelos dois métodos. Atualmente o método de contagem é exigido pelo IBAMA-AM como ferramenta fundamental para o manejo nas diversas localidades onde ele ocorre (CASTELLO, 2004).

Dessa forma, adota-se o resultado da contagem de pirarucus adultos do ano anterior como base para solicitar a cota do ano corrente, prevendo-se a remoção de aproximadamente $30 \%$ dos adultos contados, deixando-se os $70 \%$ do restante de adultos, como forma de assegurar a reprodução e a continuidade da população. Além disso, há acompanhamento da flutuação da população da espécie na área de manejo, o que é fundamental para as decisões de percentuais solicitados de captura (VIANA et al., 2007).

As contagens de pirarucu feitas pelos pescadores ao longo de mais de uma década, mostraram que as densidades populacionais de pirarucu apresentaram tendências de crescimento em cerca de quatro vezes, nas localidades monitoradas (ARANTES, 2009). Como as cotas de pesca são determinadas a partir do levantamento dos estoques, o aumento nas densidades de pirarucu refletiu no aumento equivalente da produção.

Em 2010, foram produzidos $220.523 \mathrm{~kg}$ de pirarucu em todas as áreas assessoradas pelo Instituto Mamirauá, gerando uma receita de $\mathrm{R} \$ 962.367,80$. No primeiro ano de manejo, em 1999, a produção foi bem menor: $3.000 \mathrm{~kg}$ de pirarucu. 
Exemplos desta natureza comprovam que através de projetos de manejo de recursos pesqueiros, tem se mostrado como uma forma eficiente de promoção da conservação dos recursos naturais.

\section{CONCLUSÃO}

Existe a interdependência do homem e da natureza, essa ligação é mais evidente e mais íntima entre as populações tradicionais. E o equilíbrio da relação homem natureza é fundamental para a garantia de um ambiente saudável e para a manutenção da biodiversidade.

O conhecimento tradicional, portanto, está enraizado no jeito de ser e viver das populações em que se manifestam, constituindo projeção de sua própria cultura, além de integrar importante aspecto do direito ambiental, relacionado à biodiversidade.

O proveito econômico passível de ser alcançado com o uso dos conhecimentos tradicionais associados, especialmente na área de manejo, tem conferido uma dimensão patrimonial a esse conjunto de saberes. Assim sendo concluímos que um dos modos de alcançarmos a sustentabilidade ambiental poderá ser pelo manejo de espécies. Exemplo desta natureza comprovam que através de projetos de manejo de recursos pesqueiros, tem se mostrado como uma forma eficiente de promoção da conservação dos recursos naturais, assim exemplificado na Reserva de Desenvolvimento Sustentável de Mamirauá.

\section{REFERÊCIAS BIBLIOGRÁFICAS}

ALENCAR, Aline Ferreira. A Proteção dos Conhecimentos Tradicionais Associados ao Patrimônio Genético da Amazônia Brasileira. Manaus: 2004.

Análise Jurídica sobre a biopirataria relacionada aos conhecimentos tradicionais associados ao patrimônio genético da Amazônia Brasileira. CONPEDI, 2006.

AMARAL, E. S. R. A comunidade e o mercado: os desafi os na comercialização de pirarucu manejado das Reservas Mamirauá e Amanã, Amazonas - Brasil. Uakari, v. 3, n. 2, p. 7-17, dez. 2007.

ARANTES, C. C. Ecologia do pirarucu Arapaima gigas (Schinz, 1822) na várzea da Reserva de Desenvolvimento Susntentável Mamirauá, Amazonas, Brasil. 2009. 72 f. Il. Dissertação (Mestrado) - Programa de Pós Graduação em Zoologia, Universidade Estadual de Santa Cruz, Ilhéus, 2009. 
BALTODANO, Javier (coord.). La Diversidad de Plantas y el Conocimiento Tradicional en Nuestras Comunidades: Problemas en torno a la protección y conservación del conocimiento tradicional y ejemplos de usos de las plantas en el Cantón de Upala y áreas aledañas, Zona Norte, Costa Rica. San José: COECOCEIBA. 2003.

BRASIL. Constituição da República Federativa do Brasil: Brasília: Senado Federal, 1988. Disponível em: < www.planalto.gov.br/ccivil_03/constituicao/constitui\%C3\%A7ao.htm>. Acesso em: 18 fev. 2016.

CAMARGO, Serguei Aily Franco de.; CAMARGO, Thaísa Rodrigues Lustosa de. O manejo da pesca do pirarucu Arapaima Gigas na fronteira peru, brasil e Colômbia. CONPEDI: Fortaleza-CE, 2010.

CASTELLO, L. A method to count pirarucu: fi shers, assessment and management. North American Journal of Fisheries Management, v. 24, p. 379-389, 2004.

CERDEIRA, Regina Glória Pinheiro. Acordo de pesca como instrumento de gestão participativa na Amazônia. Manaus: Programa de Pós-Graduação em Direito Ambiental da Universidade do Estado do Amazonas, Dissertação de Mestrado, 2009.

CUNHA, Manoela Carneiro, Conhecimento sem Reconhecimento-Atraso na Vida das Populações Tradicionais e ao País. Com Ciência Ambiental, São Paulo, n 1, p. 61, jul. 2006.

FAO. The State of the World Fisheries and Aquaculture. Rome, FAO, 2004, p. 153. . Increasing the Contribution of Small-scale Fisheries to Poverty Alleviation and Food Security. FAO Technical Guidelines for Responsible Fisheries, 10, 2005, p. 79.

KIHWELO, Paul Faustin. Indigenous Knowledge: What is it? How and why do we protect it?, In: Journal of World Intellectual Property, v.8, n.3, p.345-359, 2005.

LEVI-STRAUSS, C. O pensamento selvagem. $6^{\text {a }}$ ed. Campinas, São Paulo: Papirus, 2006

MAMIRAUÁ: Plano de Manejo. Brasília: Sociedade Civil Mamirauá, SCM, 1996.

MCGRATH, David G. et al. Manejo Comunitário da pesca nos lagos de várzea do baixo Amazonas. Belem: Museu Paraense Emílio Goeldi. 1993. INSTITUTO DE DESENVOLVIMENTO SUSTENTÁVEL MAMIRAUÁ. Plano diretor do IDSM: 20062009. Brasília: IDSM, 2006.

ORGANIZAÇÃO DAS NAÇÕES UNIDAS - ONU. Convenção sobre Diversidade Biológica. Disponível em: <www.mma.gov.br/estruturas/sbf_chm_rbbio/_arquivos/ cdbport_72.pdf >. Acesso em: 12 mar. 2016.

QUEIROZ, H. L.; SARDINHA, A. D. A preservação e o uso sustentado dos pirarucus (Arapaima gigas, Osteoglossidae) em Mamirauá. In: QUEIROZ, H. L.; CRAMPTON, W. G .R. (Org.). Estratégias para manejo dos recursos pesqueiros em Mamirauá. Brasília: SCM; CNPq/MCT, 1999 
RODRIGUEZ, José Rodrigo. Propriedade intelectual e conhecimentos tradicionais: avaliação crítica da disciplina jurídica brasileira. Relatório de Pesquisa apresentado ao Ministério da Justiça/ PNUD, no projeto "Pensando o Direito", Referência PRODOC BRA 07/004. São Paulo, 2014.

SANTOS, G. M.; SANTOS, A. C. M. Sustentabilidade da pesca na Amazônia. Estudos Avançados, v. 19, n. 54, p. 165-182, 2005.

SOUZA, Karine de; LOCATELLI, Liliana. Proteção jurídica dos conhecimentos tradicionais pelo Instituto das indicações geográficas. CONPEDI: UFMG/FUMEC/DOM HELDER CÂMARA, Belo Horizonte, 2015.

SOARES, Ines Virginia Prado. Direito ao (do) Patrimônio Cultural Brasileiro. Belo Horizonte: Forum, 2009.

VIANA, J. P.; CASTELLO, L.; DAMASCENO, J. M. B.; AMARAL, E. S. R.; ESTUPIÑÁN, G. M. B.; ARANTES, C.; BATISTA, G. S.; GARCEZ, D. S. BARBOSA, S. Manejo Comunitário do Pirarucu Arapaima gigas na Reserva de Desenvolvimento Sustentável Mamirauá - Amazonas, Brasil. In: ÁREAS Aquáticas Protegidas como Instumento de Gestão Pesqueira. Brasília: Ministério do Meio Ambiente ; IBAMA, 2007.

WANDSCHEER, Clarissa Bueno. Impactos da legislação nacional na proteção de saberes Tradicionais: contribuição para a sua reprodução ou Mecanismo para a sua extinção?. CONPEDI: Brasília - DF, 2008. 